\title{
Outcomes after Carotid Angioplasty and Stenting in Symptomatic Octogenarians
}

\author{
M.A. Almekhlafi, P.L. Couillard, A. Pandya, N. Shobha, W.F. Morrish, \\ J.H. Wong, M.D. Hill
}

\begin{abstract}
Objective: Octogenarians were excluded from participation in many carotid endarterectomy trials due to the high complication rates observed in past studies. However, stroke resulting from carotid stenosis is expected to increase with the aging population. Moreover, advances in Carotid Angioplasty and Stenting (CAS) techniques have resulted in perceived improved safety of this procedure. We sought to review our experience with carotid stenting in symptomatic octogenarians with an emphasis on short-term outcomes and complications. Methods: This is a retrospective longitudinal cohort study of all symptomatic patients who underwent CAS in our center between 1997 and 2007. Thirty-day stroke and death rates, and length of hospitalization were compared between the symptomatic octogenarians and non-octogenarians. Results: A total of 214 procedures were performed on 211 symptomatic patients (56 females). Fifty-nine patients (14 females) were octogenarians. The median (interquartile range) age on procedure date for the octogenarian cohort was 83 (4) years. Periprocedural death occurred in two (3.4\%) octogenarians and five (3.3\%) non-octogenarians (p $=0.97)$. At 30 days from the procedure, stroke occurred in four $(6.8 \%)$ octogenarians and seven $(4.6 \%)$ non-octogenarians $(\mathrm{p}=0.52)$. The mean hospital stay (4.8 days) was not different between the two cohorts. Age was not a predictor of the 30-day risk of composite stroke or death. Conclusion: The complications rate observed in octogenarians was not significantly higher than non-octogenarians. Our findings suggest that octogenarians should be included in randomized trials examining CAS to better define the risk-benefit profile of this procedure in the elderly.
\end{abstract}

RÉSUMÉ: Résultats de l'angioplastie carotidienne et de la mise en place d'une endoprothèse chez des octogénaires symptomatiques. Objectif : Les octogénaires ont été exclus de plusieurs essais cliniques portant sur l'endartérectomie carotidienne à cause du taux élevé de complications observé dans les études antérieures. Cependant, avec le vieillissement de la population, il est à prévoir que l'accident vasculaire cérébral dû à une sténose carotidienne sera de plus en plus fréquent. De plus, cette intervention est perçue comme étant plus sûre à cause des progrès au niveau des techniques d'angioplastie carotidienne et de mise en place d'une endoprothèse (ACEP). Nous avons révisé notre expérience concernant la mise en place d'une endoprothèse carotidienne chez des octogénaires symptomatiques en mettant l'emphase sur les résultats à court terme et les complications. Méthode : Il s'agit d'une étude longitudinale rétrospective portant sur une cohorte constituée de tous les patients symptomatiques qui ont subi une ACEP dans notre centre entre 1997 et 2007 . Nous avons comparé les taux d'accident vasculaire cérébral, les taux de décès et la durée d'hospitalisation entre les octogénaires symptomatiques et les non-octogénaires. Résultats : Au total, 214 interventions ont été effectuées chez 211 patients symptomatiques, dont 56 femmes. Cinquante-neuf de ces patients étaient des octogénaires, dont 14 femmes. L'âge médian (écart interquartile) au moment de l'intervention était de 83 (4) ans pour la cohorte d'octogénaires. Deux $(3,4 \%)$ octogénaires et $5(3,3 \%)$ non-octogénaires $(p=0,97)$ sont décédés dans la période périopératoire. Quatre octogénaires $(6,8 \%)$ et 7 non-octogénaires $(4,6 \%)$ ont subi un AVC $(\mathrm{p}=0,52)$ au cours des 30 jours suivant l'intervention. La durée moyenne d'hospitalisation ( 4,8 jours) était la même dans les deux cohortes. L'âge ne prédisait pas le risque combiné d'AVC ou de décès dans les 30 jours suivant l'intervention. Conclusion : Le taux de complication observé chez les octogénaires n'était pas significativement plus élevé que celui observé chez les non-octogénaires. Selon nos observations, les octogénaires devraient être inclus dans les essais randomisés portant sur l'ACEP pour mieux définir le profil de risque et de bénéfice de cette intervention chez les patients âgés.

Can. J. Neurol. Sci. 2011; 38: 446-451

\section{OBJECTIVE}

Carotid stenosis is a major cause of ischemic strokes and transient ischemic attacks (TIA), accounting for about $20 \%$ of all cases $^{1}$. Randomized trials have shown a clear benefit of carotid endarterectomy (CEA) plus medical therapy over medical therapy alone in reducing the risk of recurrent strokes in symptomatic carotid stenosis $\mathrm{s}^{2,3}$. Carotid artery stenting (CAS) has emerged as a potential alternative for carotid revascularization. Several randomized trials among symptomatic patients have reported early safety results slightly favoring carotid endarterectomy ${ }^{4,5}$ but long-term efficacy appears similar. The Stenting and Angioplasty with Protection for Patients at High Risk for Endarterectomy (SAPPHIRE) trial reported equivalent safety, among stented patients; however, this result was due to better safety in preventing major cardiac events, not stroke events $^{6}$. Nevertheless, with improvement in CAS devices and

From the Departments of Clinical Neurosciences (MAA, PLC, AP, NS, JHW, MDH), Community Health Sciences (MAA, MDH), Diagnostic Imaging (WFM, MDH), and Medicine (MDH), University of Calgary, Calgary, Alberta, Canada; Department of Internal Medicine (MAA), King Abdulaziz University, Jeddah, Kingdom of Saudi Arabia.

Received October 5, 2010. Final Revisions Submitted November 23, 2010. Correspondence to: Mohammed A Almekhlafi, Calgary Stroke Program, Department of Clinical Neurosciences, University of Calgary, 3330 Hospital Drive NW, Calgary, Alberta, T2N 4N1, Canada. 
techniques, CAS safety is increasing as demonstrated in the Carotid Revascularization Endarterectomy vs. Stent Trial (CREST) trial that reported a four year primary composite outcome in $7.2 \%$ of those treated with CAS. ${ }^{7}$

Carotid stenosis results in up to $40 \%$ of strokes in octogenarians $^{8}$. This number is expected to increase with the aging population ${ }^{9}$. However, octogenarians have been excluded from major randomized trials of CEA due to the putative high complications and increased comorbidities associated with advanced age ${ }^{2,10}$. The lead-in phase of the multicenter CREST reported a complication rate of $12.1 \%$ in octogenarians compared to $2.8 \%$ in the younger patients ${ }^{11}$. This can be at least partially attributed to technical difficulties due to increased tortuosity of the arteries, and to the risk of embolization from extensive atherosclerotic changes in the aorta. However, the
SAPPHIRE trial found CAS to be non-inferior to CEA although $20 \%$ of the study population were octogenarians ${ }^{6}$.

We reviewed the experience with CAS in octogenarians at our centre. Our goal was to assess procedural safety of this procedure in the elderly and younger populations.

\section{Methods}

This is a retrospective longitudinal cohort study of all CAS cases performed between 1997 and 2007 at the Foothills Medical Centre in Calgary, Alberta, Canada. The center provides tertiary comprehensive and consolidated stroke care to Calgary and surrounding southern Alberta, and southeastern British Columbia with a catchment population of about 1.5 million persons. Nearly all CAS procedures during the study period were done at the Foothills Medical Centre; less than five cases were

Table 1: Clinical characteristics of the symptomatic cohorts

\begin{tabular}{|c|c|c|c|}
\hline & All & $\begin{array}{l}\text { Non- octogenarians } \\
\qquad \mathbf{N} \text { (percent) }\end{array}$ & $\begin{array}{c}\text { Octogenarians } \\
\mathrm{N} \text { (percent) }\end{array}$ \\
\hline Number of Procedures & 211 & $152(72)$ & $59(28)$ \\
\hline Median Age (IQR) & $73(13)$ & $70(11)$ & $83(4)$ \\
\hline \multicolumn{4}{|l|}{ Risk Factors } \\
\hline CAD & $102(48.3)$ & $70(46.1)$ & $32(54.2)$ \\
\hline COPD & $38(18)$ & $26(17.1)$ & $12(20.3)$ \\
\hline $\mathrm{DM}$ & $52(24.6)$ & $45(29.6)$ & $7(11.9)$ \\
\hline PVD & $25(11.8)$ & $12(7.9)$ & $13(22)$ \\
\hline HTN & $177(83.9)$ & $130(85.5)$ & $47(79.7)$ \\
\hline Current Smoking & $64(30.3)$ & $57(37.5)$ & $7(11.9)$ \\
\hline \multicolumn{4}{|l|}{ Qualifying Event } \\
\hline Retinal & $42(19.9)$ & $33(21.7)$ & $9(15.3)$ \\
\hline TIA & $92(43.6)$ & $66(43.4)$ & $26(44.1)$ \\
\hline Stroke & $80(37.9)$ & $56(36.8)$ & $24(40.7)$ \\
\hline \multicolumn{4}{|l|}{ High Risk Features } \\
\hline Ischemic Heart Disease & $70(33.2)$ & $49(32.2)$ & $21(35.6)$ \\
\hline Severe Pulmonary Disease & $16(7.5)$ & $12(7.9)$ & $4(6.8)$ \\
\hline Contralateral Occlusion & $16(7.5)$ & $12(7.9)$ & $4(6.8)$ \\
\hline Recurrent Stenosis after CEA & $14(6.6)$ & $11(7.2)$ & $3(5.1)$ \\
\hline Two or more features & $16(7.5)$ & $11(7.2)$ & $5(8.5)$ \\
\hline
\end{tabular}

CAD: coronary artery disease, COPD chronic obstructive pulmonary disease, DM: diabetes mellitus, HTN: hypertension, PVD: peripheral vascular disease, TIA: transient ischemic attacks 
done at one other hospital in Calgary and these are not included in the analysis. Procedures were done by five endovascular therapists (four interventional neuroradiologists and one endovascular neurosurgeon). All patients who underwent CAS were included in the analysis. Three patients who underwent stenting to facilitate advancing the catheter for intra-arterial therapy in the setting of acute ischemic stroke were excluded. Details of demographics, CAS indication, vascular risk profile, time from symptom onset to CAS, and procedure-related information were collected. The out-patient records were used for the 30-day outcomes. Follow-up visits were attended by a stroke neurologist or a vascular neurosurgeon. When the 30-day follow-up data were not available $(n=8)$, the vital status of the individual at that time was used instead. We compared the risk factor profile and outcomes of the symptomatic octogenarians and non-octogenarians. Different data from the same cohort have been previously published ${ }^{12}$.

Carotid stenosis was defined as narrowing - of any degreeof the internal carotid artery or common carotid artery. The degree of stenosis used was defined angiographically using the North American Symptomatic Carotid Endarterectomy Trial (NASCET) criteria and categorized into moderate (50 to $70 \%$ stenosis), severe (more than 70\%) and near occlusion (more than $95 \%$ stenosis with collapsed distal internal carotid artery). Acute ischemic stroke was defined as acute onset of persistent neurological symptoms by history or physical examination verifiable by diagnostic imaging. A retinal event was defined as transient or permanent monocular vision loss ipsilateral to carotid stenosis. Transient ischemic attack was defined as any focal neurological deficit caused by cerebral ischemia that resolved within 24 hours from onset. Stroke severity was defined as major if inpatient rehabilitation was required. A patient was considered "high surgical risk" when any of the following was present: significant cardiac disease, severe pulmonary disease, contralateral carotid occlusion, previous neck surgery or radiation, age of 80 years or more, or recurrent carotid stenosis after CEA. Significant cardiac disease was defined by a prior history of coronary angioplasty or cardiac bypass surgery. Severe pulmonary disease was defined as any pulmonary disease requiring home oxygen therapy. Neurologic death was defined as death related to a massive stroke or intracerebral hemorrhage.

All procedures were performed at the Foothills Medical Center. All patients were pre-medicated with aspirin and clopidogrel; where patients had known adverse reactions to Aspirin, clopidogrel was used alone. Stenting procedures were performed under intravenous conscious sedation supported by anesthesiology. A common femoral artery access was used in all cases. Intravenous unfractionated heparin was administered as a bolus dose prior to the stent deployment. Stents of various sizes and models were used. The most common stent utilized was the Carotid WALLSTENT (Boston Scientific, Natick MA). Preangioplasty dilatation was performed using a $4 \mathrm{~mm}$ balloon and post-stenting dilatation was done using a $5 \mathrm{~mm}$ balloon. Distal protection devices were used in all cases since 1999 and the device most commonly used was the Filter Wire EZ Embolic Protection System (Boston Scientific, Natick MA). Six patients (all non-octogenarian) underwent CAS without the use of distal protection devices. A femoral artery closure device was used to close the puncture site. The term "intra-procedure events" represent all the complications that occurred while the patients were in the angiography suite including arterial dissection, transient ischemic attack, stroke, arrhythmias, and hemodynamic instability. Patients were monitored in a specialized neurological monitoring unit until stable for discharge or transfer to a regular ward. Aspirin was continued indefinitely post-procedure while clopidogrel was routinely continued until two months after the procedure.

An informed consent was provided by the patients or their surrogates for the CAS procedure. This study was approved by the Foothills Medical Center ethics review board.

There were three chart reviewers (MAA, AP, and NS) and any disagreements on review were resolved by consensus. The cohort demographics and vascular risk factors were described in absolute numbers and percentages. Two patient cohorts were defined by the patient age on the date of the procedure as less than 80 years or 80 years or older. Measured variables are reported in median and interquartile range (IQR), and compared by Mann Whitney U test. Categorical variables were compared by Chi-square test. A multivariable logistic regression model was used to assess factors associated with the outcomes. All testing was two-tailed and was done at the 0.05 level of significance. Analyses were done using Stata 10 software (Stata Corp, College Station, TX).

\section{RESULTS}

A total of 214 CAS procedures were performed on 211 patients (56 females) between May 1997 and December 2007. Three patients, all non-octogenarians, underwent bilateral stenting. Fifty-nine patients (14 females) were 80 years or older.

The median IQR age on procedure date for the octogenarian cohort was 83 (4) years, and 70 (11) years for the nonoctogenarians. All patients were referred for CAS after assessment by a stroke neurologist or a vascular neurosurgeon. The octogenarian cohort had slightly more patients with coronary artery disease (CAD) and peripheral vascular disease (PVD) while the non-octogenarian cohort had more patients with diabetes mellitus (DM), and more smokers (Table 1). About a third of the patients in each cohort had a history of ischemic heart disease. Two or more features that confer high surgical risk - excluding age - were present in $8.5 \%$ of the octogenarian cohort and $7.1 \%$ in the non-octogenarians. All patients in both cohorts received antiplatelet agents by the day of the procedure. Among 211 patients, nine were treated in the MAVErIC study ${ }^{13}$, one was treated in the International Carotid Stenting Study $(\mathrm{ICSS})^{14}$ and 10 in the CREST lead-in phase ${ }^{10}$; all of these studies have been published or reported in abstract form.

The median (IQR) time from symptoms onset to CAS was 8.6 (18.9) weeks (Table 2). About $32.2 \%$ of the octogenarians had CAS within two weeks of symptoms onset compared to $25.8 \%$ in the non-octogenarians $(\mathrm{p}=0.09)$. There was no difference in the degree of carotid stenosis between the two groups. The majority of carotid stenosis cases in both groups were related to atherosclerosis. The mean hospital stay was 4.8 days and was not different in the two cohorts.

Intra-procedure stroke occurred in one octogenarian and one non-octogenarian patient $(\mathrm{p}=0.5)$. One octogenarian patient had a transient leg weakness during the procedure which completely resolved. Three patients in the non-octogenarian cohort and one 
Table 2: Procedure characteristics

\begin{tabular}{lccc}
\hline & \multicolumn{1}{c}{ All } & Non- octogenarians & Octogenarians \\
& N (percent) & N (percent) & N (percent) \\
& (Total=211) & (Total=152) & (Total=59) \\
\hline Time from Symptom to CAS & & & \\
Median weeks (IQR) & $8.6(18.9)$ & $9.1(20)$ & $4.3(14)$ \\
Number within 2 weeks (\%) & $59(27.6)$ & $40(25.8)$ & $19(32.2)$ \\
Degree of stenosis & & & $11(18.6)$ \\
$50-69 \%$ & $37(17.5)$ & $119(78.3)$ & $42(71.2)$ \\
$\geq 70$ & $161(76.3)$ & $10(6.6)$ & $6(10.2)$ \\
Near occlusion & $16(7.6)$ & $64(42.1)$ & $26(44.1)$ \\
Bilateral stenosis & $90(42.7)$ & & $26(44.1)$ \\
Side Stented* & & $78(51.3)$ & $33(55.9)$ \\
Right & $104(48.8)$ & $77(50.1)$ & \\
Left & $110(52.1)$ & & \\
\hline
\end{tabular}

* Three patients underwent bilateral stenting.

octogenarian patient had a brief episode of asystole. Three patients in the octogenarian cohort had an episode of bradycardia.

Thirty-day follow-up data (Table 3) were available for 198 patients $(93.8 \%)$. Of those, 15 patients (five octogenarians) were alive at the time of follow-up but were not interviewed in person. The 30-day survival rate in octogenarians is $96.5 \%$ and $96 \%$ in non-octogenarians $(\mathrm{p}=0.76)$. A composite outcome of stroke and death of any cause occurred in six (10.2\%) octogenarians and in $12(7.9 \%)$ non-octogenarians $(\mathrm{p}=0.6)$. Three $(5.1 \%)$ octogenarians suffered a major stroke or death at the 30-day follow up compared to eight $(5.6 \%)$ non-octogenarians $(\mathrm{p}=$ $0.89)$. Octogenarian status was not a predictor of the 30-day risk of stroke or death, $\left(\mathrm{OR}=1.7, \mathrm{CI}_{95}\right.$ 0.7-4.1) even after adjustment for sex, degree of stenosis, and timing of the procedure.

\section{Discussion}

Our results do not suggest that octogenarians have a significantly different 30-day outcome after CAS compared to non-octogenarians. If there is a true difference in adverse outcomes, our experience shows that it is not as large as has been previously suggested. Similar results have been found in other studies which reported a 30-day adverse events rate of 3 to $12 \%$ in octogenarians ${ }^{15-18}$, while other cohorts had complications rates reaching as high as $25 \%^{19,20}$, especially when distal protection devices were not used ${ }^{18}$. This variation can be attributed to the small sample size in some of these reports and possibly to a lack of standard use of antiplatelet therapy or distal protection devices ${ }^{19}$. In addition, a large proportion of the octogenarians in some of the series were asymptomatic which is associated with better outcomes compared to symptomatic patients. In our cohort, all patients were symptomatic. Finally, many factors may increase the risk of CAS in octogenarians including extensive aortic arch atheroma, increased arterial tortuosity, and greater propensity to bleeding with dual antiplatelet therapy ${ }^{11}$.

Age influenced the outcome of CAS in randomized trials but the outcome of CAS in octogenarians has not been directly addressed in a randomized clinical trial. The SAPPHIRE trial randomized 334 high surgical risk patients to receive CAS or $\mathrm{CEA}^{6}$. Thirty-seven patients were 80 years of age or older. The primary endpoint (a composite of death, stroke, or myocardial infarction (MI) within 30 days after the intervention or death or ipsilateral stroke between 31 days and 1 year) occurred in $12.2 \%$ of the CAS arm vs. $20.1 \%$ in the CEA arm. The authors did not report age-specific results and did not describe a higher incidence of complications in the octogenarians. A point of criticism for this study was the randomization of patients with unstable angina and recurrent stenosis despite the high rate of complications expected with surgery in those patients. A number of large prospective cohorts reported on the safety of CAS in symptomatic octogenarians. In a report on 144 CAS procedures in octogenarians (93 symptomatic), Setacci and his colleagues 
Table 3: Carotid artery stenting outcomes

\begin{tabular}{|c|c|c|c|}
\hline & $\begin{array}{c}\text { All } \\
\text { N (percent) }\end{array}$ & $\begin{array}{c}\text { Non- octogenarians } \\
\text { N (percent) } \\
\text { (Total=152) }\end{array}$ & $\begin{array}{c}\text { Octogenarians } \\
\text { N (percent) } \\
\text { (Total=59) }\end{array}$ \\
\hline Mean Days of Hospital Stay & 4.8 & 4.5 & 5.4 \\
\hline \multicolumn{4}{|l|}{ Outcomes } \\
\hline \multicolumn{4}{|c|}{ Procedure-related events } \\
\hline None & $194(91.9)$ & $144(92.9)$ & $50(84.7)$ \\
\hline Asymptomatic Dissection & $5(2.3)$ & $3(1.9)$ & $2(3.4)$ \\
\hline Transient Ischemic Attack & $1(0.5)$ & 0 & $1(1.7)$ \\
\hline Minor Stroke & $1(0.5)$ & $1(0.7)$ & 0 \\
\hline Major Stroke & $1(0.5)$ & 0 & $1(1.7)$ \\
\hline Cardiac Dysrhythmia & $7(3.3)$ & $3(1.9)$ & $4(6.8)$ \\
\hline Hemodynamic Instability & $4(1.9)$ & $3(1.9)$ & $1(1.7)$ \\
\hline \multicolumn{4}{|c|}{ Overall 30-day outcome } \\
\hline Mortality (any cause) & $7(3.3)$ & $5(3.3)$ & $2(3.5)$ \\
\hline Neurologic Death & $4(1.9)$ & $4(2.6)$ & 0 \\
\hline Non-neurologic Death & $3(1.4)$ & $1(0.7)$ & $2(3.5)$ \\
\hline Major Stroke & $4(1.9)$ & $3(2)$ & $1(1.8)$ \\
\hline Minor Stroke & $7(3.4)$ & $4(2.6)$ & $3(5.3)$ \\
\hline Transient Neurologic Deficit & $5(2.4)$ & $3(2)$ & $2(3.5)$ \\
\hline Hyperperfusion Syndrome & $2(0.9)$ & $1(0.7)$ & $1(1.8)$ \\
\hline Myocardial Infarction & $2(0.9)$ & $1(0.7)$ & $1(1.8)$ \\
\hline Heart Failure & $1(0.5)$ & 0 & $1(1.8)$ \\
\hline
\end{tabular}

found no difference in 30-day risk of stroke or death between the younger and older age groups ${ }^{21}$. Similarly, in a cohort of 418 octogenarians (one third symptomatic), a 3.3\% 30-day cumulative incidence of death, stroke, or myocardial infarction was reported ${ }^{22}$. The Arbeitsgemeinschaft Leitende Kardiologische Krankenhausarzte (ALKK) is one of the largest prospective registries enrolling about 322 octogenarians between 1996 and $2005^{23}$. The rate of in-hospital death or stroke was $5.5 \%$ in octogenarians and $3.2 \%$ in the non-octogenarians. They reported an increase in CAS performed in octogenarians who represented $5.9 \%$ of the cohort in 1996 but $13.7 \%$ in 2005 . This increase calls for better evidence to guide the management options in octogenarians. More recently the CREST $\operatorname{trial}^{7}$ showed a significant interaction between age and treatment outcome as patients older than 70 years attained more benefit from CEA compared to CAS. We used 80 year-old as the age cutoff in this cohort since the majority of studies exploring the effect of age on CAS outcome used the same cutoff.

In our cohort, there was a trend toward fewer complications over time as no 30-day deaths occurred in our cohort after 2005. These findings suggest that case selection, better technology, and improved technique are major determinants of the outcome of CAS in octogenarians.

Our study has limitations. This is a single tertiary center experience of non-randomized patients which limits its generalizability. Octogenarians who underwent the procedure were carefully selected and reviewed by a panel of stroke neurologists, neuroradiologists, and vascular neurosurgeons. Data were collected retrospectively and true 30-day follow-up was not available in eight patients. Long-term follow-up (e.g. 
one-year) data were not evaluated in this study and we cannot comment on the long-term safety or durability of CAS. The cause of 30-day death for those who died outside the hospital could not be always precisely documented.

\section{Conclusion}

In this cohort of 59 octogenarians, the observed 30-day risk of stroke or death was similar to that of the non-octogenarians. Our findings suggest that CAS in this age group may not be as dangerous as previously described and octogenarians should not necessarily be excluded from participation in multicenter prospective studies of CAS.

\section{Disclosure}

The Calgary Stroke Program has been a participating site in the MAVERIC trial, ICSS, and CREST which are all trials examining carotid artery stenting.

\section{REFERENCES}

1. Fairhead JF, Rothwell PM. The need for urgency in identification and treatment of symptomatic carotid stenosis is already established. Cerebrovasc Dis. 2005;19(6):355-8.

2. Inzitari D, Eliasziw M, Gates P, et al. The causes and risk of stroke in patients with asymptomatic internal-carotid-artery stenosis. North American Symptomatic Carotid Endarterectomy Trial Collaborators. N Engl J Med. 2000 Jun 8;342(23):1693-700.

3. Halliday A, Mansfield A, Marro J, et al. Prevention of disabling and fatal strokes by successful carotid endarterectomy in patients without recent neurological symptoms: randomised controlled trial. Lancet. 2004 May 8;363(9420):1491-502.

4. Ringleb PA, Allenberg J, Bruckmann H, et al. 30 day results from the SPACE trial of stent-protected angioplasty versus carotid endarterectomy in symptomatic patients: a randomised noninferiority trial. Lancet. 2006 Oct 7;368(9543):1239-47.

5. Navin DM, Sacco WJ. Science and evidence-based considerations for fulfilling the SALT triage framework. Disaster Med Public Health Prep. 2010 Mar;4(1):10-12; author reply 12.

6. Gurm HS, Yadav JS, Fayad P, et al. Long-term results of carotid stenting versus endarterectomy in high-risk patients. N Engl J Med. 2008 Apr 10;358(15):1572-9.

7. Gussoni G, Campanini M, Silingardi $M$, et al. In-hospital symptomatic venous thromboembolism and antithrombotic prophylaxis in internal medicine. Findings from a multicenter, prospective study. Thromb Haemost. 2009 May;101(5):893-901.

8. Gelabert HA, Moore WS. Carotid endarterectomy without angiography. Surg Clin North Am. 1990 Feb;70(1):213-23.
9. Ramirez-Lassepas M. Stroke and the aging of the brain and the arteries. Geriatrics. 1998 Sep;53 Suppl 1:S44-8.

10. Endarterectomy for asymptomatic carotid artery stenosis. Executive committee for the asymptomatic carotid atherosclerosis study. JAMA. 1995 May 10;273(18):1421-8.

11. Hobson RW, 2nd, Howard VJ, Roubin GS, et al. Carotid artery stenting is associated with increased complications in octogenarians: 30-day stroke and death rates in the CREST leadin phase. J Vasc Surg. 2004 Dec;40(6):1106-11.

12. Shobha N, Almekhlafi MA, Pandya A, et al. Carotid stenting in asymptomatic carotid stenosis: the Calgary experience. Can J Neurol Sci. 2010;37(5):568-73.

13. Hill MD, Morrish W, Soulez G, et al. Multicenter evaluation of a self-expanding carotid stent system with distal protection in the treatment of carotid stenosis. AJNR Am J Neuroradiol. 2006 Apr;27(4):759-65.

14. Tang TY, Howarth SP, Miller SR, et al. Correlation of carotid atheromatous plaque inflammation using USPIO-enhanced MR imaging with degree of luminal stenosis. Stroke. $2008 \mathrm{Jul} ; 39(7)$ : 2144-7.

15. Shawl F, Kadro W, Domanski MJ, et al. Safety and efficacy of elective carotid artery stenting in high-risk patients. J Am Coll Cardiol. 2000 Jun;35(7):1721-8.

16. Stanziale SF, Marone LK, Boules TN, et al. Carotid artery stenting in octogenarians is associated with increased adverse outcomes. J Vasc Surg. 2006 Feb;43(2):297-304.

17. Lam RC, Lin SC, DeRubertis B, Hynecek R, Kent KC, Faries PL. The impact of increasing age on anatomic factors affecting carotid angioplasty and stenting. J Vasc Surg. 2007 May;45(5): 875-80.

18. Linfante I, Andreone V, Akkawi N, Wakhloo AK. Internal carotid artery stenting in patients over 80 years of age: single-center experience and review of the literature. J Neuroimaging. 2009 Apr;19(2):158-63. Epub 2008 Sep 17.

19. Chastain HD, 2nd, Gomez CR, Iyer S, et al. Influence of age upon complications of carotid artery stenting. UAB neurovascular angioplasty team. J Endovasc Surg. 1999 Aug;6(3):217-22.

20. Villalobos HJ, Harrigan MR, Lau T, et al. Advancements in carotid stenting leading to reductions in perioperative morbidity among patients 80 years and older. Neurosurgery. 2006 Feb;58(2):23340; discussion 233-40.

21. Setacci C, de Donato G, Chisci E, et al. Is carotid artery stenting in octogenarians really dangerous? J Endovasc Ther. 2006 Jun;13 (3):302-9.

22. Grant A, White C, Ansel G, Bacharach M, Metzger C, Velez C. Safety and efficacy of carotid stenting in the very elderly. Catheter Cardiovasc Interv. 2010 Apr 1;75(5):651-5.

23. Zahn $\mathrm{R}$, Ischinger $\mathrm{T}$, Hochadel $\mathrm{M}$, et al. Carotid artery stenting in octogenarians: results from the ALKK carotid artery stent (CAS) Registry. Eur Heart J. 2007 Feb;28(3):370-5. 